\title{
Physicochemical transformation and algal toxicity of engineered nanoparticles in surface water samples ${ }^{\not 2}$
}

\author{
Luqing Zhang a , Jingyi Li a, Kun Yang a, b, Jingfu Liu ${ }^{c}$, Daohui Lin ${ }^{\text {a, b, * }}$ \\ a Department of Environmental Science, Zhejiang University, Hangzhou 310058, China \\ b Zhejiang Provincial Key Laboratory of Organic Pollution Process and Control, Zhejiang University, Hangzhou 310058, China \\ ' State Key Laboratory of Environmental Chemistry and Ecotoxicology, Research Center for Eco-Environmental Sciences, Chinese Academy of Sciences, P. O. \\ Box 2871, Beijing 100085, China
}

\section{A R T I C L E I N F O}

\section{Article history:}

Received 1 August 2015

Received in revised form

19 December 2015

Accepted 20 December 2015

Available online 30 December 2015

\section{Keywords:}

Natural water

Dissolution

Aggregation

Nanotoxicity

\begin{abstract}
A B S T R A C T
Most studies on the behavior and toxicity of engineered nanoparticles (NPs) have been conducted in artificial water with well-controlled conditions, which are dramatically different from natural waters with complex compositions. To better understand the fate and toxicity of NPs in the natural water

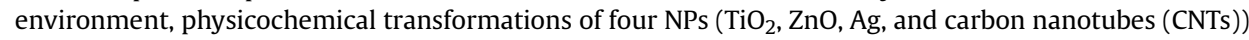
and their toxicities towards a unicellular green alga (Chlorella pyrenoidosa) in four fresh water and one seawater sample were investigated. Results indicated that water chemistry had profound effects on aggregation, dissolution, and algal toxicity of the NPs. The strongest homoaggregation of the NPs was associated with the highest ionic strength, but no obvious correlation was observed between the homoaggregation of NPs and $\mathrm{pH}$ or dissolved organic matter content of the water samples. The greatest dissolution of ZnO NPs also occurred in seawater with the highest ionic strength, while the dissolution of $\mathrm{Ag}$ NPs varied differently from $\mathrm{ZnO}$ NPs. The released $\mathrm{Zn}^{2+}$ and especially $\mathrm{Ag}^{+}$mainly accounted for the algal toxicity of $\mathrm{ZnO}$ and $\mathrm{Ag}$ NPs, respectively. The NP-cell heteroagglomeration occurred generally for CNTs and Ag NPs, which contributed to the observed nanotoxicity. However, there was no significant correlation between the observed nanotoxicity and the type of NP or the water chemistry. It was thus concluded that the physicochemical transformations and algal toxicities of NPs in the natural water samples were caused by the combined effects of complex water quality parameters rather than any single influencing factor alone. These results will increase our knowledge on the fate and effects of NPs in the aquatic environment.
\end{abstract}

() 2015 Elsevier Ltd. All rights reserved.

\section{Introduction}

Advances in nanotechnology have promoted the widespread production and application of engineered nanoparticles (NPs), causing increased discharge of NPs into aquatic environments (Garner and Keller, 2014; Gottschalk et al., 2013). For example, ZnO and $\mathrm{TiO}_{2}$ NPs are widely utilized in cosmetic, coating, paint, and electronic industries (Dange et al., 2007; Franklin et al., 2007; Hall et al., 2009). Ag NPs are employed in a variety of consumer products due to their antimicrobial activity (Dobrzynska et al., 2014), and carbon nanotubes (CNTs) have a range of applications, such as biomedicine (Cha et al., 2013), sewage treatment (Kar et al., 2012),

\footnotetext{
* This paper has been recommended for acceptance by Eddy Y. Zeng.

* Corresponding author. Department of Environmental Science, Zhejiang University, Hangzhou 310058, China.

E-mail address: lindaohui@zju.edu.cn (D. Lin).
}

electronics, and sensors (Bennett et al., 2013). Consequently, environmental concentrations of NPs, though being modeled and/or measured to be in levels of $\mu \mathrm{g} / \mathrm{L}$ or much less, were estimated to increase exponentially (Gottschalk et al., 2009, 2013). Moreover, environmental concentrations of some NPs in their application or deposition area could be extremely high, e.g., $0.75-50 \mathrm{~g} / \mathrm{L}$ zero valent iron NPs were used in in situ field scale remediation of contaminated soil and groundwater (Grieger et al., 2010). More and more case studies indicated that the discharged NPs could pose serious risks to aquatic organisms (Ma et al., 2013; Schultz et al., 2014).

In aquatic environments, various environmental parameters, such as $\mathrm{pH}$, ionic strength, and dissolved organic matter (DOM), will alter the physicochemical properties and the colloidal behaviors of NPs. It was reported that the aggregation of ZnO NPs increased with increasing ionic strength and was much stronger at 
the $\mathrm{pH}$ close to the point of zero charge $\left(\mathrm{pH}_{\mathrm{pzc}}\right)$ of NPs (Bian et al., 2011). In addition, the dissolution of ZnO NPs was observed at both low and high $\mathrm{pH}$ and was enhanced by humic acid at high $\mathrm{pH}$ (Bian et al., 2011). The aggregation and dissolution of Ag NPs increased with increasing ionic strength (Chambers et al., 2014) but was inhibited in the presence of $\mathrm{Cl}^{-}$(Lin et al., 2015). CNTs demonstrated enhanced stability in the presence of DOM (Lin and Xing, 2008; Lin et al., 2010a), which was greatly dependent on pH and ionic strength as well (Lin et al., 2009, 2012a). Water-chemistrydependent homoaggregations of $\mathrm{TiO}_{2}$ NPs (Lin et al., 2015) and other NPs (Chekli et al., 2015; Conway et al., 2015) have also been reported. In spite of the intensive investigations of the effects of well-controlled water quality parameters on the physicochemical transformations of NPs, the understanding of their fate and behavior in natural water is still in its infancy (Lowry et al., 2012). The combined effects of diverse environmental factors may make the behaviors of NPs in natural water different from those in artificial waters. It is necessary to strengthen the research on the physicochemical transformation of NPs in a real water environment for the scientific assessment of environmental behaviors and biological effects of the NPs.

An increasing number of studies have reported the toxicity of NPs to aquatic organisms with a focus on the effect of water chemistry (Schultz et al., 2014). The higher toxicity of Ag NPs to algal cells was observed in acidic media (Oukarroum et al., 2014) and media with high ionic strength (Chambers et al., 2014), owing to the increased release of silver ions. However, the inverse phenomenon was reported in several studies where Ag NPs demonstrated decreased toxicity in media with higher ionic strength (Gao et al., 2009; Harmon et al., 2014). Mitigated bactericidal effects of ZnO NPs (Li et al., 2013) and $\mathrm{TiO}_{2}$ NPs (Lin et al., 2014) were also observed in media with high $\mathrm{pH}$ or ionic strength. DOMs generally alleviated the nanotoxicity, owing to their complexation with the NP-released toxic ions, the hindrance of NP-organism contact, and/ or the reduced generation of reactive oxygen species (Kim et al., 2013; Lin et al., 2012b; Zhao et al., 2013). Enhanced nanotoxicity, however, was also observed in the presence of DOMs (Wang et al., 2011; Zhang et al., 2015). Until now, most studies have been conducted in artificial waters, which are dramatically different from natural waters with complex compositions. Very few studies have investigated the toxicity of NPs toward aquatic organisms including algae in natural water samples (Bhuvaneshwari et al., 2015; Dalai et al., 2013). The complex water chemistry of natural waters would complicate the toxicity of NPs, which merits more investigation.

We hypothesize that there may be no clear correlation between the physicochemical transformation and toxicity of NPs and the water chemistry of natural waters because of the coexistence of multiple water quality parameters. Aggregation, dissolution, and algal toxicity of NPs in five natural water samples with distinct physicochemical properties were, therefore, investigated. Nanoscale $\mathrm{TiO}_{2}, \mathrm{ZnO}, \mathrm{CNTs}$, and Ag particles were used as the typical NPs because of their extensive usage. The unicellular green alga $(C$. pyrenoidosa), a widely used model aquatic organism, was selected as the test organism. The correlations between water chemistry and aggregation, dissolution, and algal toxicity of the NPs were specifically discussed. We believe that our findings will increase the knowledge on the fate and effects of NPs in the aquatic environment.

\section{Materials and methods}

\subsection{Collection and characterization of water samples}

Five surface water samples with distinct physicochemical properties were collected in October 2013 from a fish pond in Tangxi town (TX, N 30 $28^{\prime} 26^{\prime \prime}$, E $120^{\circ} 11^{\prime} 19^{\prime \prime}$ ) of Hangzhou city, a countryside river in Dongyang city (DY, N 29 $17^{\prime} 23^{\prime \prime}$, E $120^{\circ} 14^{\prime}$ $30^{\prime \prime}$ ), the Dongjiang river in Shaoxing city (SX, N 30 $4^{\prime} 25^{\prime \prime}, \mathrm{E}$ $\left.120^{\circ} 27^{\prime} 29^{\prime \prime}\right)$, the Taihu lake ( $\left.\mathrm{TH}, \mathrm{N} 31^{\circ} 5^{\prime} 55^{\prime \prime}, \mathrm{E} 120^{\circ} 15^{\prime} 56^{\prime \prime}\right)$, and the


China. The collected water samples were centrifuged $(3500 \mathrm{~g}$, $15 \mathrm{~min}$ ) to remove large particles, filtered through $0.45 \mu \mathrm{m}$ polytetrafluoroethylene filters to remove microorganisms, and then stored at $4{ }^{\circ} \mathrm{C}$ in dark. The five water samples represented various water environments: TX being a fishery-affected water body, DY standing for the freshwater far away from cities, SX representing the river water passing through a city, TH being the freshwater from one of the biggest lake in China, and TZ being the seawater in an estuary mixed with freshwater.

The conductivity of the samples was analyzed with a conductivity meter (DDS-11A, Yoke Instrument Co., China). The content of total organic carbon (TOC) was measured by a TOC analyzer (TOC$\mathrm{VCPH}$, Shimadzu, Japan) to reflect the DOM content. The pH and zeta potential were determined using a pH meter (Mettler Toledo, Columbus, USA) and a Zetasizer (Nano ZS90, Malvern Instruments, $\mathrm{UK})$ at $25^{\circ} \mathrm{C}$, respectively. Inductively coupled plasma mass spectrometry (ICP-MS, 7500 Series, Agilent, USA) was applied to determine cation concentrations in the surface water samples after acid digestion. Anions excluding $\mathrm{CO}_{3}^{2-}$ in the samples were analyzed using ion chromatography (861 Advanced Compact IC, Metrohm, Switzerland). The concentration of $\mathrm{CO}_{2}^{3-}$ was expressed as the inorganic carbon content as measured by the TOC analyzer.

\subsection{Characterization of the NPs in the water samples}

The used $\mathrm{ZnO}(20 \pm 5 \mathrm{~nm})$ and anatase $\mathrm{TiO}_{2}(12 \pm 4 \mathrm{~nm}) \mathrm{NPs}$ were purchased from Zhejiang Hongsheng Materials Technology Co., China. Ag NPs $(46 \pm 25 \mathrm{~nm})$ were obtained from Beijing Daoking Technology Ltd., China. The multiwalled CNTs $(70 \pm 9 \mathrm{~nm}$ in the outer diameter and $3.2 \pm 0.9 \mu \mathrm{m}$ in length) were from Shenzhen Nanotech Port Co., China and were further purified by $\mathrm{HCl}$ solution before use. We had previously characterized and used all the NPs in other studies (Ji et al., 2011; Long et al., 2012; Lin et al., 2015), and their selected properties are summarized in Table S1 in the Supporting information.

The NPs $(100 \mathrm{mg} / \mathrm{L})$ were sonicated $\left(100 \mathrm{~W}, 40 \mathrm{kHz}, 25^{\circ} \mathrm{C}\right)$ into the water samples for $30 \mathrm{~min}$, and their zeta potentials and hydrodynamic sizes were measured by the Zetasizer at $25{ }^{\circ} \mathrm{C}$. To determine the dissolution of $\mathrm{ZnO}$ and Ag NPs in the water samples, the concentrations of metal ions in the supernatants of the NP suspensions collected after the centrifugation (2500 g, $15 \mathrm{~min}$ ) and the filtration through $0.22 \mu \mathrm{m}$ polytetrafluoroethylene filters were quantified by the ICP-MS.

\subsection{Settling experiment}

NP-NP and cell-cell homoaggregations and NP-cell heteroagglomeration in the water samples were investigated following the procedures described in our previous study (Ma et al., 2015). Briefly, algal cells and NPs were individually suspended or mixed in the water samples; the individual suspensions or mixtures were immediately transferred to cuvettes, and their absorbance at $660 \mathrm{~nm}$ (Lin et al., 2012b; Long et al., 2012) was thereafter monitored. Since the CNTs were more hydrophobic and settled much faster than the other NPs, the absorbance of CNT suspensions was monitored at intervals of $1 \mathrm{~s}$ within $2 \mathrm{~h}$, whereas the absorbance of $\mathrm{ZnO}, \mathrm{TiO}_{2}$, and $\mathrm{Ag}$ suspensions was recorded for $12 \mathrm{~h}$ at intervals of $15 \mathrm{~min}$. The settling curves, normalized absorbance vs. settling time curves, were subsequently plotted. The co- (mix) and additive- 
(sum) settling curves presented the absorbance of the mixtures and the sum of independent absorbance of individual suspensions changing along with time, respectively. The NP-cell heteroagglomeration occurred when the co-settling curve was below the additive-settling curve, and the discrepancy indicated the extent of heteroagglomeration.

\subsection{Algal viability assay}

The green alga $C$. pyrenoidosa used in this study was from the Institute of Wuhan Hydrobiology, Chinese Academy of Sciences and was cultured in the medium recommended by the Organization for Economic Co-operation and Development (OECD) (with compositions detailed in the Supporting Information).

The algal viability assay was conducted following similar procedures described in the previous study (Dalai et al., 2013). Before the inoculation of algal cells, $250 \mathrm{~mL}$ Erlenmeyer flasks were autoclaved at $0.1 \mathrm{MPa}$ for $20 \mathrm{~min}$. The NPs were suspended in the water samples by sonication ( $\left.100 \mathrm{~W}, 40 \mathrm{kHz}, 25{ }^{\circ} \mathrm{C}, 15 \mathrm{~min}\right)$. Subsequently, the algal cells $\left(2.5 \times 10^{6}\right.$ cells $\left./ \mathrm{mL}\right)$ were exposed to the NP suspensions $(0,10$, and $100 \mathrm{mg} / \mathrm{L})$ and were then kept in an incubation shaker $(110 \mathrm{rpm})$ at $25{ }^{\circ} \mathrm{C}$ with illumination by incandescent lights $\left(100 \pm 5 \mu \mathrm{E} \mathrm{m}^{-2} \mathrm{~s}^{-1}\right.$, light:dark of 14:10 h). Since the algal cells were cultured in the water samples with insufficient nutrition for growth, the cell numbers were counted after $24 \mathrm{~h}$ of culture with a counting chamber under a light microscope (LM, CX21, Olympus, Japan). Exposure without NPs in each of the water samples served as blank controls. The viabilities (ratios of the cell numbers exposed to NPs to the corresponding control after $24 \mathrm{~h}$ of culture) were calculated to represent the algal toxicities of the NPs in the water samples. In addition, cell viability in the water samples without NPs was calculated as the ratio of cell density after the culture to the initial density. The metal ions in the algaeexposed water samples (100 $\mathrm{mg} / \mathrm{L}$ NPs) were measured by the ICP-MS to assess the dissolution of NPs in the presence of algae.

To evaluate the potential contribution of metal ions dissolved from $\mathrm{ZnO}$ and $\mathrm{Ag}$ NPs to the nanotoxicity, the toxicities of $\mathrm{ZnCl}_{2}$ and $\mathrm{AgNO}_{3}$ solutions to the algal cells were also assayed. Based on the measurements of NP dissolution, comparable exposure concentrations were selected. The exposure followed the procedures mentioned above for the NPs.

\subsection{Statistical analyses}

Each treatment in the toxicity tests was performed in triplicate, and the values are expressed as mean \pm standard deviation in the tables and figures. The differences between the controls and treatments were analyzed by analysis of variance (ANOVA). Linear regression was applied to analyze the correlation between toxicity and the physicochemical transformation of NPs and the water quality parameters. The degree of correlation was determined by the correlation coefficient $(R)$, and the level of significance was accepted at $p<0.05$.

\section{Results and discussion}

\subsection{Properties of the water samples}

Table 1 shows selected properties of the surface water samples. All of the samples had circumneutral $\mathrm{pH}$ values, ranging from 7.06 to 7.59. Ionic strength varied greatly within the range of 3.19-213 mM. The content of DOM ranged from 6.74 to $23.3 \mathrm{mg} \mathrm{C}$ L. Zeta potentials were all negative, indicating the existence of negatively-charged colloids in the samples. In particular, the sample $\mathrm{TZ}$, as seawater, had the highest $\mathrm{pH}$ and, notably, its ionic

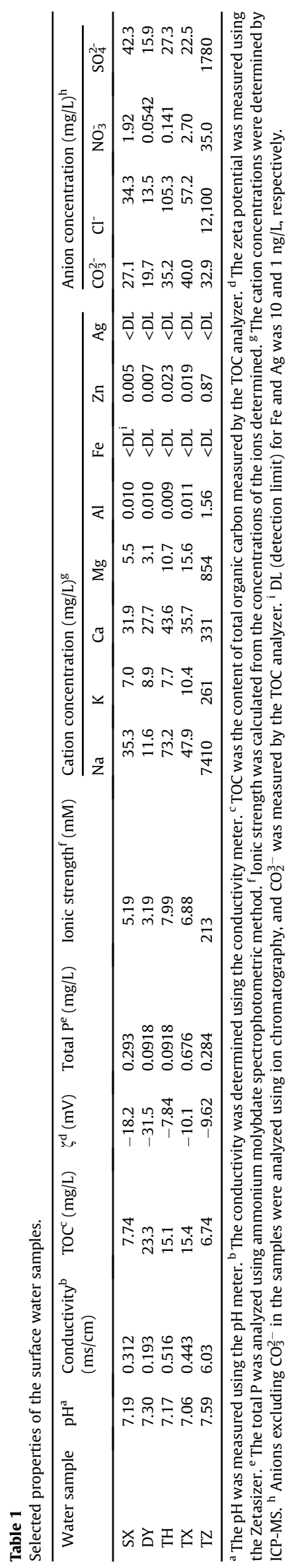


strength and conductivity were far greater than the other samples; the sample DY had the lowest ionic strength and zeta potential but the highest DOM content.

\subsection{Changes in zeta potential and hydrodynamic size of the NPs in the water samples}

Zeta potentials and hydrodynamic sizes of the NPs in the water samples are shown in Fig. 1. The NPs were all negatively charged in the samples. Zeta potentials of the NPs in DY with the highest TOC content were largely the lowest among the water samples, probably due to the adsorption of DOM and/or the abundance of negatively-charged colloids in the sample. The absolute zeta potentials of all NPs, except $\mathrm{ZnO}$, were the lowest in $\mathrm{TZ}$, suggesting the weakest electrostatic repulsion among the NPs in the seawater. Consequently, the NPs severely aggregated in the seawater, as indicated by the largest hydrodynamic sizes in $\mathrm{TZ}$ among the water samples.

\subsection{Homoaggregations of the NPs in the water samples}

The NP-type- and water-type-dependent settling curves of NPs in the water samples are illustrated in Fig. 2. CNTs settled rapidly, especially in the seawater sample. $\mathrm{ZnO}$ and $\mathrm{TiO}_{2}$ NPs settled more rapidly than Ag NPs, probably owing to their smaller sizes and thus more severe aggregations. As expected, the settling curves of all NPs in the seawater were far below those in the fresh water samples, while the discrepancy in the settlings of each NP among the fresh water samples was not such distinct. The settling curves of ZnO NPs nearly overlapped in the fresh water samples. The settling of the other three NPs was apparently the weakest in DY with the lowest ionic strength among the water samples.

The above result revealed that the homoaggregation of NPs in the water samples could be regulated by ionic strength. Electrolytes would compress the electrical double layer of NPs and enhance homoaggregation in the water samples (Lin et al., 2010b). Previous studies found that the aggregation of NPs is strongly dependent on $\mathrm{pH}$ and increases as the solution $\mathrm{pH}$ approaches $\mathrm{pH}_{\mathrm{pzc}}$ of the NPs due to the attenuation of energy barrier preventing the aggregation (Guzman et al., 2006; Bian et al., 2011). In addition, the increased electrostatic and steric repulsions due to the adsorption of DOM on the surfaces of NPs are supposed to promote the stabilization of NPs (Lin et al., 2010b; Thio et al., 2011). However, there was no obvious correlation between the settling of NPs and $\mathrm{pH}$ or DOM of the water samples in this study, which may be due to the fact that the variation in $\mathrm{pH}$ or DOM content of the natural water samples was not great enough to make a significant difference in the stabilization of NPs and/or the combined effect from other water quality parameters, including ionic strength.

\subsection{Dissolutions of the NPs in the water samples}

The concentrations of ions dissolved from $\mathrm{ZnO}$ and $\mathrm{Ag}$ NPs $(100 \mathrm{mg} / \mathrm{L})$ are listed in Table 2 . The dissolution of ZnO NPs in the seawater $\mathrm{TZ}$ was much greater than in the other water samples. The greatest dissolution of Ag NPs was, however, detected in DY, followed by that in the seawater and then in the other three water samples.

The correlations between the water quality parameters and the dissolutions are illustrated in Fig. S1 in the Supporting information, with the fitted parameters given in Table S2. Significant positive correlation ( $\mathrm{R}=0.908, p=0.021$ ) was found between $\mathrm{pH}$ and the dissolution of ZnO NPs in the water samples. However, no significant correlation was observed between the dissolution of Ag NPs and $\mathrm{pH}$ (Fig. S1A). It was reported that some metal oxide NPs showed increased solubility at acidic pH (Bian et al., 2011), which appeared to be different from the results obtained in this study. Here, the effect of such a narrow $\mathrm{pH}$ range on the dissolutions may be indistinct and masked by other environmental factors to varying degrees.


Fig. 1. Zeta potentials and hydrodynamic sizes of the NPs in the water samples. Error bars represent standard deviations $(\mathrm{n}=3)$. 

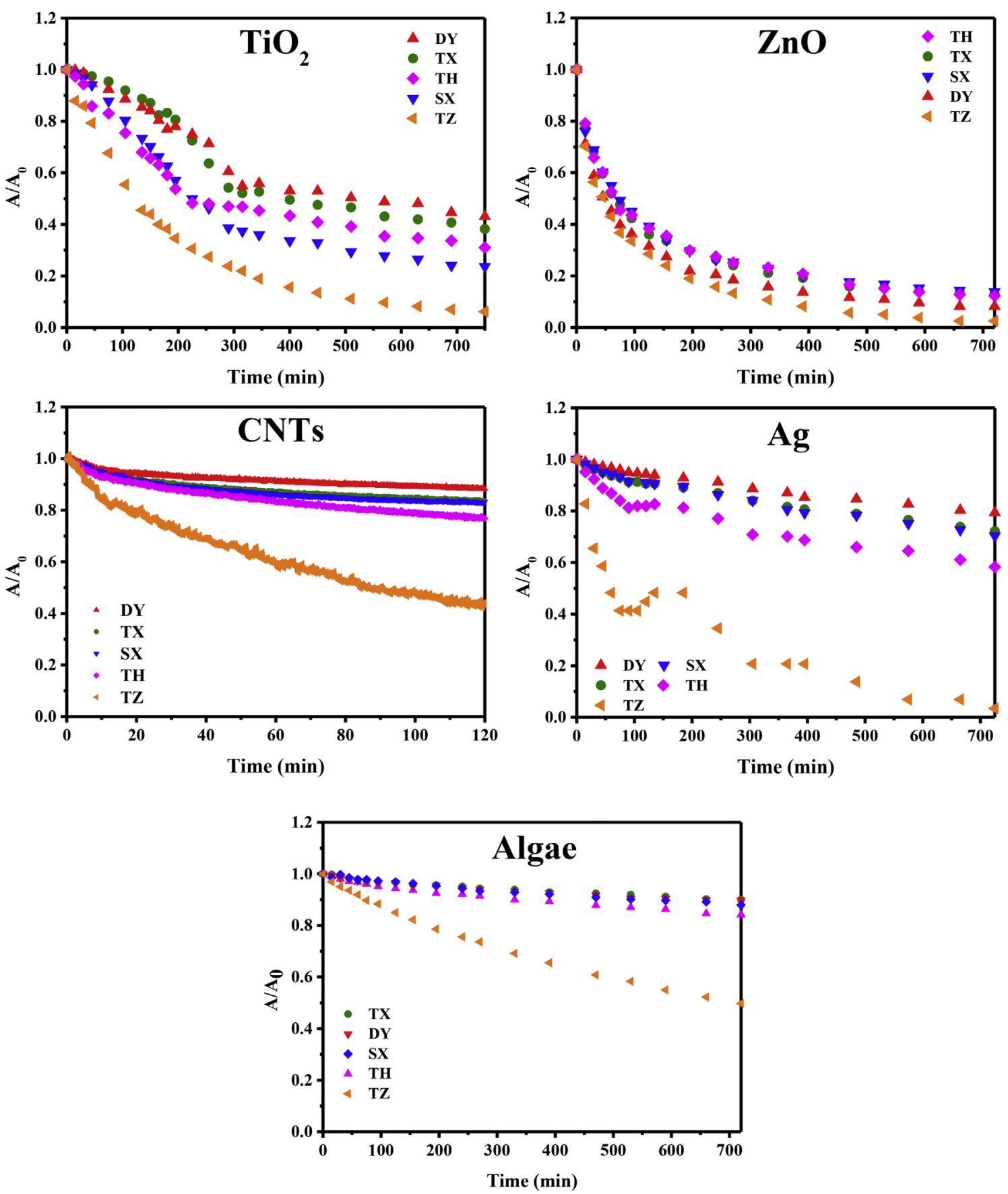

Fig. 2. Changes of the normalized absorbance at $660 \mathrm{~nm}\left(\mathrm{~A} / \mathrm{A}_{0}\right)$ of the NPs and algal cells in the water samples against the settling time.

Table 2

The concentrations of metal ions dissolved from $\mathrm{ZnO}$ and Ag NPs in the water samples.

\begin{tabular}{lllcccc}
\hline \multirow{2}{*}{ NPs } & Water samples & \multicolumn{6}{l}{ Concentration $(\mu \mathrm{g} / \mathrm{L})$} \\
\cline { 3 - 7 } & & DY & SX & TH & TX & TZ \\
\hline \multirow{2}{*}{ ZnO } & Blank sample & 1290 & 1150 & 854 & 931 & 5520 \\
& Alga-exposed sample & 1150 & 824 & 602 & 579 & 1480 \\
\multirow{2}{*}{ Ag } & Blank sample & 1080 & 259 & 40.0 & 45.6 & 656 \\
& Alga-exposed sample & 1030 & 383 & 127 & 256 & 213 \\
\hline
\end{tabular}

The much higher ionic strength and dissolution of ZnO NPs in the seawater TZ led to an apparent positive correlation $(R=0.992$, $p=0.001$ ) between the dissolution of $\mathrm{ZnO}$ NPs and ionic strength of the water samples (Table S2). The presence of high concentrations of certain anions, such as $\mathrm{Cl}^{-}$and $\mathrm{SO}_{4}^{2-}$, was supposed to serve as $\mathrm{Zn}^{2+}$ binding ligands, thus promoting the dissolution of $\mathrm{ZnO}$ in $\mathrm{TZ}$ (Miao et al., 2010). There was, however, no linear correlation between the ionic strength and the dissolution of Ag NPs in the water samples. It is assumed that the released $\mathrm{Ag}^{+}$could react with $\mathrm{Cl}^{-}$in the natural water samples, forming $\mathrm{AgCl}$ precipitation and consequently reducing the dissolved $\mathrm{Ag}^{+}$concentration to some extent (Lin et al., 2015). The sample DY had the lowest $\mathrm{Cl}^{-}$content though with the lowest ionic strength, which could possibly explain the highest apparent dissolution of Ag NPs in DY.

There was no linear correlation between the DOM content and 
the dissolution of $\mathrm{ZnO}$ or Ag NPs (Fig. S1C). The presence of humic acid was reported to increase the dissolution of $\mathrm{ZnO}$ NPs at high $\mathrm{pH}$, but the opposite occurred to Ag NPs (Bian et al., 2011; Liu and Hurt, 2010). Although the dissolution of metal-based NPs was supposed to be tightly dependent upon the DOM content, these findings were mainly from experiments performed under laboratory conditions with other parameters fixed, regardless of complex components in natural waters. Our study suggests that the dissolution of metalbased NPs in natural waters is a result of the combined effect of complex water chemistry and not dominated by a sole water quality parameter.

\subsection{The NP-cell heteroagglomeration in the water samples}

The settling curves of algal cells in the water samples are shown in Fig. 2. There was no obvious difference among the settlings in the fresh water samples, as indicated by the nearly overlapping settling curves. Notably, settling in the seawater was much stronger than those in the fresh water samples, suggesting that high ionic strength could enhance the homoaggregation of algal cells in addition to the NPs.

Fig. 3 shows the normalized co- and additive-settling curves of NPs and algal cells in the water samples. The CNT-cell and Ag-cell co-settling curves were largely below their additive-settling curves, suggesting the occurrence of CNT-cell and Ag-cell heteroagglomerations. Exceptionally, no apparent discrepancy between co- and additive-settling curves of CNTs and algal cells was found in the seawater sample. The dramatic enhancement of homoaggregations of both CNTs and cells in the seawater could be responsible for the inhibition of CNT-cell heteroagglomeration, as reported in our previous study (Ma et al., 2015). The nearly overlapping co- and additive-settling curves of ZnO NPs and algal cells in all of the water samples indicated the very weak $\mathrm{ZnO}$-cell heteroagglomeration. This could also be explained by the strong homoaggregation of $\mathrm{ZnO}$ NPs, as indicated by the relatively larger hydrodynamic sizes (Fig. 1) and largely lower settling curves (Fig. 2) of ZnO NPs as compared with those of the other three NPs. As for the $\mathrm{TiO}_{2} \mathrm{NPs}$, the co-settling curve was lower than the additivesettling curve in the seawater sample, indicating the existence of $\mathrm{TiO}_{2}$-cell heteroagglomeration; while the co-settling curves were above the additive-settling curves in the four fresh water samples. DOM in the fresh water samples could help to hinder the $\mathrm{TiO}_{2}$-cell heteroagglomeration. NPs adhering to and agglomeration with cells would facilitate NP damage to membranes and entrance of cells, as reported for $\mathrm{TiO}_{2}$, CNTs, and ZnO NPs with algal cells (Lin et al., 2012b; Long et al., 2012; Zhang et al., 2015; Chen et al., 2012).

\subsection{Toxicities of the NPs in the water samples}

Due to insufficient nutrients, the density of algal cells was reduced to varying degrees after incubating in the water samples without NPs for $24 \mathrm{~h}$, as illustrated in Fig. 4A. The viabilities of algal cells in the water samples in the presence of 10 and $100 \mathrm{mg} / \mathrm{L} \mathrm{NPs}$ are shown in Fig. 4B and C, respectively. Amitava Mukherjee and coauthors reported the viabilities of freshwater algae (Scenedesmus obliquus) in a natural water sample from a local lake in India were $82.77 \pm 1.11 \%$ exposed to $1 \mathrm{mg} / \mathrm{L}$ anatase $\mathrm{TiO}_{2} \mathrm{NPs}(10-50 \mathrm{~nm})$ for $24 \mathrm{~h}$ under the UV-irradiation condition (Dalai et al., 2013) and
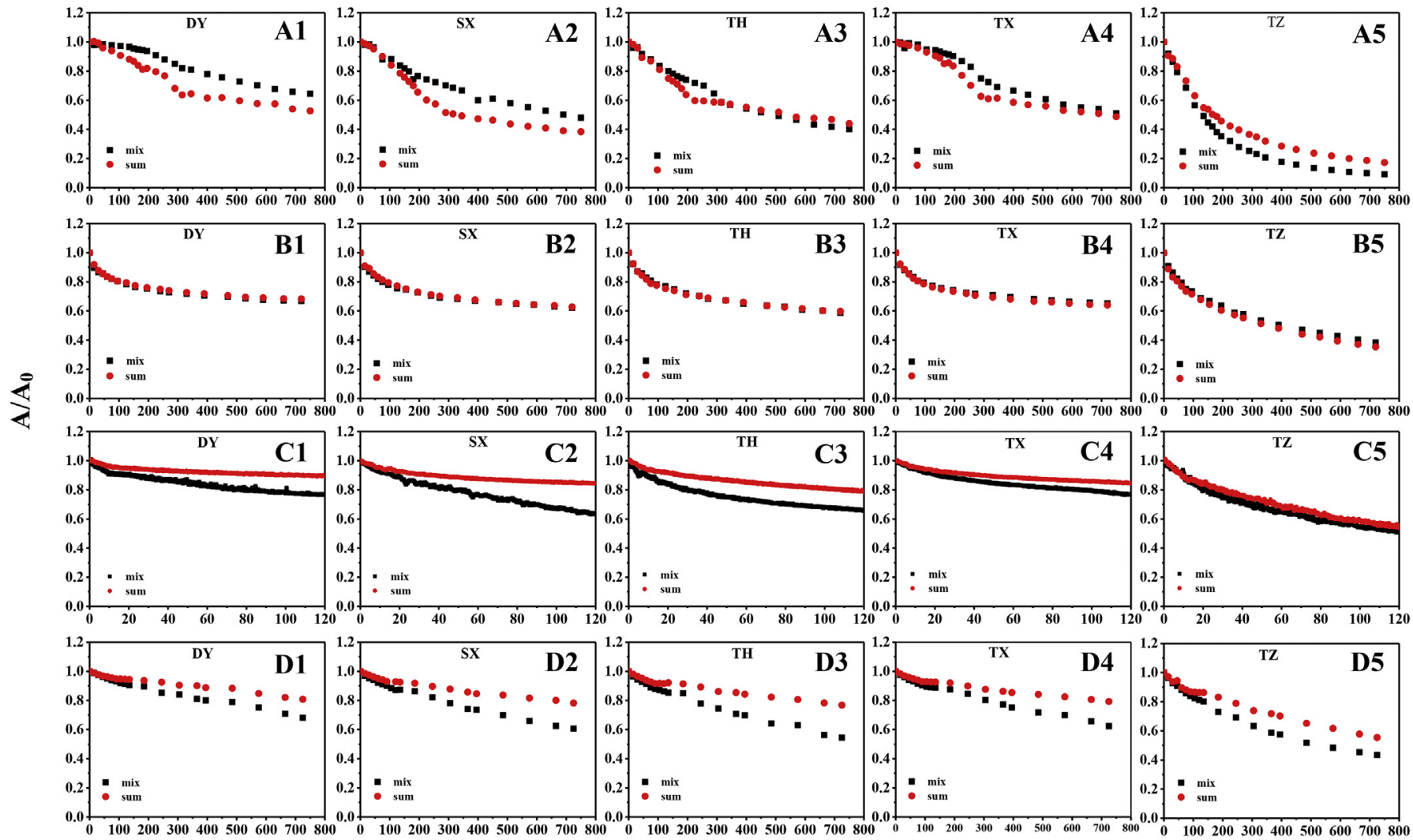

Time (min)

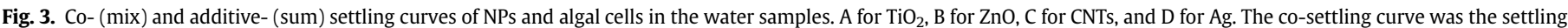

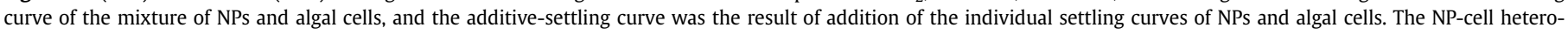
agglomeration occurred when the co-settling curve was below the additive-settling curve, and the discrepancy indicated the extent of the heteroagglomeration. 







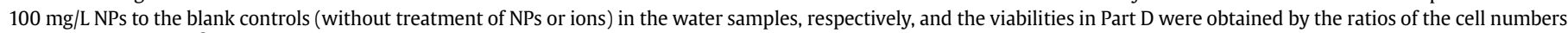

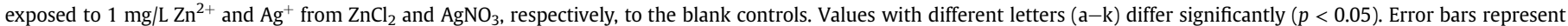
standard deviations $(\mathrm{n}=3)$.

74.2-76.3\% exposed to $1 \mathrm{mg} / \mathrm{L}$ ZnO NPs ( $40-44 \mathrm{~nm}$ ) for $72 \mathrm{~h}$ under the visible light conditions (Bhuvaneshwari et al., 2015). Due to the different organisms, NPs, and experimental conditions used, it is difficult to compare the results from them and this study. No similar algal toxicity data of other NPs in surface water samples are available for a comparison with the result of this study. As compared with the reported algal toxicity of similar NPs in the synthetic culture media with the half growth inhibition concentrations $\left(\mathrm{IC}_{50}\right)$ of $4.9 \mathrm{mg} / \mathrm{L}$ for $\mathrm{TiO}_{2} \mathrm{NPs}$ (Lin et al., 2012b), $60 \mu \mathrm{g} \mathrm{Zn/L} \mathrm{for} \mathrm{ZnO} \mathrm{NPs}$ (Franklin et al., 2007), $2.28 \mu \mathrm{g} / \mathrm{L}$ for Ag (Chen et al., 2013), and $14.5 \mathrm{mg} / \mathrm{L}$ for CNTs (Zhang et al., 2015), the toxicities of the NPs towards algae were mitigated in the natural water samples in this study. The toxicities of the NPs varied greatly, depending on the type and concentration of NPs as well as the water sample type.

The $\mathrm{TiO}_{2}$ NPs and CNTs were largely more toxic at the higher concentration, while lower toxicity was observed for the $\mathrm{ZnO}$ and $\mathrm{Ag}$ NPs at the higher concentration. The CNTs exhibited very low toxicity at $10 \mathrm{mg} / \mathrm{L}$, and the $\mathrm{TiO}_{2} \mathrm{NPs}$ at $10 \mathrm{mg} / \mathrm{L}$ could even promote algal growth to some extent. Therefore, $100 \mathrm{mg} / \mathrm{L}$ was chosen to study the correlation between nanotoxicity and the physicochemical properties of the water samples.

Different NPs exhibited distinct toxicities towards algae, even in the same water sample. At the low concentration, the toxicities of the NPs were in a similar sequence of $\mathrm{ZnO}>\mathrm{Ag}>\mathrm{CNTs}>\mathrm{TiO}_{2}$ with a few exceptions. In contrast, the toxicities of the NPs in the samples at the high concentration largely followed the order of $\mathrm{TiO}_{2}>\mathrm{ZnO}>\mathrm{CNTs}>\mathrm{Ag}$, except that Ag NPs were more toxic than CNTs in DY, and CNTs exhibited higher toxicity than ZnO NPs in TH. The NPs showed very different toxicities in TX, with the order of $\mathrm{ZnO}>\mathrm{Ag}>\mathrm{CNTs}>\mathrm{TiO}_{2}$, which was completely opposite to that in the seawater $\mathrm{TZ}$. The $\mathrm{TiO}_{2} \mathrm{NPs}$ did not exhibit toxicity at the low concentration but appeared to be the most toxic among the four NPs, except in TX, at the high concentration.

Each type of NP showed distinct algal toxicities in different water samples. The $\mathrm{TiO}_{2}$ NPs only exhibited relatively high algal toxicity in the water samples at the high concentration with the order of DY $>\mathrm{SX}>\mathrm{TZ}>\mathrm{TH}>\mathrm{TX}$, which was quite different from the other three NPs. The toxicity of ZnO NPs in the water samples was in the sequence of TX $>\mathrm{SX}>\mathrm{DY}>\mathrm{TH}>\mathrm{TZ}$ for both concentrations. CNTs and Ag NPs also showed varied toxicities in various water samples with distinct orders.

The diverse toxicities of the NPs in the water samples demonstrated the different toxic mechanisms of the four NPs and the great effect of water chemistry on the nanotoxicity. Since dissolved metal ions from metal-based NPs are expected to be an important mechanism for nanotoxicity, the algal toxicities of $\mathrm{Zn}^{2+}$ and $\mathrm{Ag}^{+}$ ions from $\mathrm{ZnCl}_{2}$ and $\mathrm{AgNO}_{3}$, respectively, were determined (Fig. 4D). Considering the concentrations of dissolved $\mathrm{Zn}^{2+}$ and $\mathrm{Ag}^{+}$ ions in the algae-exposed samples ( $100 \mathrm{mg} / \mathrm{L})$ covered the range of $579-1480 \mu \mathrm{g} / \mathrm{L}$ and $127-1030 \mu \mathrm{g} / \mathrm{L}$, respectively (Table 2 ), the toxicities of $1 \mathrm{mg} \mathrm{Zn}{ }^{2+} / \mathrm{L}$ or $1 \mathrm{mg} \mathrm{Ag}^{+} / \mathrm{L}$ in the water samples were examined. The higher toxicity was observed for $\mathrm{Ag}^{+}$in the water samples than for $\mathrm{Zn}^{2+}$. The toxicities of $\mathrm{Ag}^{+}$ions in the five natural water samples were greater than or largely comparable with those of Ag NPs, suggesting the dominant role of released $\mathrm{Ag}^{+}$ions in the algal toxicity of Ag NPs. The toxicity of Ag NPs to a marine alga was also attributed to the dissolved $\mathrm{Ag}^{+}$ions (Miao et al., 2009). Compared with $\mathrm{ZnO}$ NPs, the toxicity of $\mathrm{Zn}^{2+}$ ions was greater or largely comparable in DY, TH, and TZ but was significantly lower in SX and TX. Therefore, the released $\mathrm{Zn}^{2+}$ ions could largely account for the observed algal toxicity of $\mathrm{ZnO}$ NPs, but there were other mechanisms, such as oxidative stress, contributing to the 
nanotoxicity in the natural water samples. A similar conclusion was obtained in our previous study that examined the algal toxicity of ZnO NPs in the OECD medium (Ji et al., 2011).

\subsection{Influencing factors on the nanotoxicity in the water samples}

Different NPs could have different toxic mechanisms, and thus the influencing factor dominating the nanotoxicity would be different. The algal toxicities of $\mathrm{TiO}_{2}$ NPs and CNTs were generally ascribed to physical interaction and oxidative stress (Lin et al., 2012b; Long et al., 2012); while the toxicities of ZnO and Ag NPs were mainly due to the ions dissolved from the NPs (Li et al., 2011; Miao et al., 2009). The CNT-cell heteroagglomeration occurred in almost all the water samples, which could contribute to the observed algal toxicity in addition to the toxic mechanisms, such as the shading effect and oxidative stress imposed by the CNTs as described in our previous study (Long et al., 2012). The $\mathrm{TiO}_{2}$-cell heteroagglomeration was only observed in the seawater sample, which suggested that the potential cell damage resulting from the NP-cell heteroagglomeration could not be the main toxic mechanism of $\mathrm{TiO}_{2}$ NPs in fresh surface waters. Enhanced oxidative stress was ascribed as the main toxic mechanism for the algal toxicity of $\mathrm{TiO}_{2} \mathrm{NPs}$ (Lin et al., 2012b). Similarly, the physical damage could not be responsible for the algal toxicity of ZnO NPs in the water samples since no agglomeration between $\mathrm{ZnO}$ NPs and cells was observed. The released $\mathrm{Zn}^{2+}$ ions could be a main cause of the algal toxicity of $\mathrm{ZnO}$ NPs, as discussed in the above section. The fact that the Ag-cell heteroagglomeration occurred in all of the water samples indicated that physical damage could contribute to the algal toxicity of $\mathrm{Ag}$ NPs. Furthermore, the released $\mathrm{Ag}^{+}$ions could greatly increase the toxicity of Ag NPs as mentioned above.

The water chemistry surely affected the physicochemical properties of NPs and could thus influence the algal toxicity of the NPs in the water samples. The correlations between the water quality parameters and the toxicities of NPs were analyzed and shown in Fig. S2 with the fitted parameters given in Table S3. Regrettably, no significant linear correlation was found between the toxicity of NPs and the DOM content or ionic strength or $\mathrm{pH}$ in the water samples. Given the diversity of the toxicity results and the complexity of the natural water samples, it is reasonable to infer that the nanotoxicity in natural environments cannot be solely dependent on any single environmental quality parameter alone but may be a result of the combined effect of various factors.

We recognize that there were some weaknesses in the experimental design of this study. The nanotoxicity of the NPs could not be effectively distinguished from the toxicity of NPs in bulk or micro-sized particles due to the lack of non-nanosized controls. Aggregates formed rapidly in the water samples though the NPs were sonicated, making it difficult to study the size effect of the NPs. Only two high concentrations of the NPs were examined, while a range of concentrations of the NPs should be applied so as to calculate some toxicological data such as $\mathrm{IC}_{50}$. In addition, more surface water samples with distinct physicochemical properties should be examined. Despite the defects, we hope that this study will encourage more specific studies in the real water environment to explore the environmental behavior and ecological effects of NPs.

\section{Conclusions}

The NPs exhibited distinct physicochemical properties in the natural water samples, which consequently led to variations of NPcell heteroagglomeration and algal toxicity. The strongest NP homoaggregation occurred in the water sample with the highest ionic strength due to the compression of the electrical double layer.
This was evidenced by the lowest absolute zeta potentials and largest hydrodynamic sizes of the NPs in the seawater among the water samples. No obvious correlation was observed between the homoaggregation of NPs and the $\mathrm{pH}$ or DOM content of the water samples. The $\mathrm{pH}$ value varied little among the water samples, and its effect on the dissolutions of $\mathrm{ZnO}$ and $\mathrm{Ag}$ NPs could be masked by the other environmental factors to varying degrees. The apparent dissolutions were not significantly related to the DOM content either. The highest ionic strength could result in the greatest dissolution of ZnO NPs in the seawater, while the presence of high concentration anionic ligands $\left(\mathrm{Cl}^{-}\right)$could precipitate the released $\mathrm{Ag}^{+}$ions and thus reduced the apparent dissolution of Ag NPs in the seawater. The dissolved $\mathrm{Zn}^{2+}$ and especially $\mathrm{Ag}^{+}$could be mainly responsible for the toxicity of $\mathrm{ZnO}$ and $\mathrm{Ag} \mathrm{NPs}$, respectively. The NPcell heteroagglomerations were also dependent on the types of NPs and water samples, which could also be involved in the observed toxicities of CNTs and Ag NPs to the algae. Among the four NPs, the anatase $\mathrm{TiO}_{2} \mathrm{NPs}$ showed relatively greater toxicity to the algae in the water samples at the high concentration. However, there was no regular variation trend of the nanotoxicity either with the type of NPs or the water chemistry. It can be concluded that both the physicochemical transformation and algal toxicity of the NPs could not be dominated by any single influencing factor alone but were the result of the combined effect of the complex water chemistry. The complex water chemistry of the natural water would pose challenges and uncertainties to the exploration of the environmental behavior and toxicity of the NPs in natural waters. The obtained results of the nanotoxicity based on the assays in culture media or simulated waters need to be verified in the real water environment.

\section{Acknowledgment}

This work was supported by the National Natural Science Foundation of China $(21525728,21337004,21477107)$, the 973 program of China (2014CB441104), and the Specialized Research Fund for the Doctoral Program of Higher Education (20130101110132).

\section{Appendix A. Supplementary data}

Supplementary data related to this article can be found at http:// dx.doi.org/10.1016/j.envpol.2015.12.041.

\section{References}

Bennett, S.W., Adeleye, A., Ji, Z., Keller, A.A., 2013. Stability, metal leaching, photoactivity and toxicity in freshwater systems of commercial single wall carbon nanotubes. Water Res. 47, 4074-4085.

Bhuvaneshwari, M., Iswarya, V., Archanaa, S., Madhu, G.M., Kumar, G.K.S., Nagarajan, R., Chandrasekaran, N., Mukherjee, A., 2015. Cytotoxicity of ZnO NPs towards fresh water algae Scenedesmus obliquus at low exposure concentrations in UV-C, visible and dark conditions. Aquat. Toxicol. 162, 29-38.

Bian, S., Mudunkotuwa, I.A., Rupasinghe, T., Grassian, V.H., 2011. Aggregation and dissolution of $4 \mathrm{~nm} \mathrm{ZnO}$ nanoparticles in aqueous environments: influence of $\mathrm{pH}$, ionic strength, size, and adsorption of humic acid. Langmuir 27, 6059-6068.

Cha, C., Shin, S.R., Annabi, N., Dokmeci, M.R., Khademhosseini, A., 2013. Carbonbased nanomaterials: multifunctional materials for biomedical engineering. ACS Nano 7, 2891-2897.

Chambers, B.A., Afrooz, A.R.M.N., Bae, S., Aich, N., Katz, L., Saleh, N.B., Kirisits, M.J., 2014. Effects of chloride and ionic strength on physical morphology, dissolution, and bacterial toxicity of silver nanoparticles. Environ. Sci. Technol. 48 (1), $761-769$.

Chekli, L., Zhao, Y.X., Tijing, L.D., Phuntsho, S., Donner, E., Lombi, E., Gao, B.Y., Shon, H.K., 2015. Aggregation behaviour of engineered nanoparticles in natural waters: characterising aggregate structure using on-line laser light scattering. J. Hazard. Mater. 284, 190-200.

Chen, P.Y., Powell, B.A., Mortimer, M., Ke, P.C., 2012. Adaptive interactions between zinc oxide nanoparticles and Chlorella sp. Environ. Sci. Technol. 46, $12178-12185$. 
Chen, Z.Z., Porcher, C., Campbell, P., Fortin, C., 2013. Influence of humic acid on algal uptake and toxicity of ionic silver. Environ. Sci. Technol. 47, 8835-8842.

Conway, J.R., Adeleye, A.S., Gardea-Torresdey, J., Keller, A.A., 2015. Aggregation, dissolution, and transformation of copper nanoparticles in natural waters. Environ. Sci. Technol. 49, 2749-2756.

Dalai, S., Pakrashi, S., Joyce Nirmala, M., Chaudhri, A., Chandrasekaran, N., Mandal, A.B., Mukherjee, A., 2013. Cytotoxicity of $\mathrm{TiO}_{2}$ nanoparticles and their detoxification in a freshwater system. Aquat. Toxicol. 138-139, 1-11.

Dange, C., Phan, T.N.T., André, V., Rieger, J., Persello, J., Foissy, A., 2007. Adsorption mechanism and dispersion efficiency of three anionic additives [poly(acrylic acid), poly(styrene sulfonate) and HEDP] on zinc oxide. J. Colloid Interface Sci. 315, 107-115.

Dobrzynska, M.M., Gajowik, A., Radzikowska, J., Lankoff, A., Dusinska, M., Kruszewski, M., 2014. Genotoxicity of silver and titanium dioxide nanoparticles in bone marrow cells of rats in vivo. Toxicology 315, 86-91.

Franklin, N.M., Rogers, N.J., Apte, S.C., Batley, G.E., Gadd, G.E., Casey, P.S., 2007. Comparative toxicity of nanoparticulate $\mathrm{ZnO}$, bulk $\mathrm{ZnO}$, and $\mathrm{ZnCl}_{2}$ to a freshwater microalga (Pseudokirchneriella subcapitata): the importance of particle solubility. Environ. Sci. Technol. 41, 8484-8490.

Gao, J., Youn, S., Hovsepyan, A., Llaneza, V.L., Wang, Y., Bitton, G., Bonzongo, J.J., 2009. Dispersion and toxicity of selected manufactured nanomaterials in natural river water samples: effects of water chemical composition. Environ. Sci. Technol. 43, 3322-3328.

Garner, K.L., Keller, A.A., 2014. Emerging patterns for engineered nanomaterials in the environment: a review of fate and toxicity studies. J. Nanopart. Res. 16, 2503.

Gottschalk, F., Sonderer, T., Scholz, R.W., Nowack, B., 2009. Modeled environmental concentrations of engineered nanomaterials $\left(\mathrm{TiO}_{2}, \mathrm{ZnO}, \mathrm{Ag}\right.$, CNT, Fullerenes) for different regions. Environ. Sci. Technol. 43, 9216-9222.

Gottschalk, F., Sun, T.Y., Nowack, B., 2013. Environmental concentrations of engineered nanomaterials: review of modeling and analytical studies. Environ. Pollut. 181, 287-300.

Grieger, K.D., Fjordboge, A., Hartmann, N.B., Eriksson, E., Bjerg, P.L., Baun, A., 2010. Environmental benefits and risks of zero-valent iron nanoparticles (nZVI) for in situ remediation: risk mitigation or trade-off? J. Contam. Hydrol. 118, 165-183.

Guzman, K.A.D., Finnegan, M.P., Banfield, J.F., 2006. Influence of surface potential on aggregation and transport of titania nanoparticles. Environ. Sci. Technol. 40, 7688-7693.

Hall, S., Bradley, T., Moore, J.T., Kuykindall, T., Minella, L., 2009. Acute and chronic toxicity of nano-scale $\mathrm{TiO}_{2}$ particles to freshwater fish, cladocerans, and green algae, and effects of organic and inorganic substrate on $\mathrm{TiO}_{2}$ toxicity. Nanotoxicology 3 (2), 91-97.

Harmon, A.R., Kennedy, A.J., Poda, A.R., Bednar, A.J., Chappell, M.A., Steevens, J.A., 2014. Determination of nanosilver dissolution kinetics and toxicity in an environmentally relevant aqueous medium. Environ. Toxicol. Chem. 33, $1783-1791$.

Ji, J., Long, Z.F., Lin, D.H., 2011. Toxicity of oxide nanoparticles to the green algae Chlorella sp. Chem. Eng. J. 170, 525-530.

Kar, S., Bindal, R.C., Tewari, P.K., 2012. Carbon nanotube membranes for desalination and water purification: challenges and opportunities. Nano Today 7, 385-389.

Kim, J.Y., Kim, K.T., Lee, B.G., Lim, B.J., Kim, S.D., 2013. Developmental toxicity of Japanese medaka embryos by silver nanoparticles and released ions in the presence of humic acid. Ecotoxicol. Environ. Saf. 92, 57-63.

Li, M., Lin, D.H., Zhu, L.Z., 2013. Effects of water chemistry on the dissolution of ZnO nanoparticles and their toxicity to Escherichia coli. Environ. Pollut. 173, 97-102.

Li, M., Zhu, L.Z., Lin, D.H., 2011. Toxicity of ZnO nanoparticles to Escherichia coli: mechanism and the influence of medium components. Environ. Sci. Technol. 45, 1977-1983.

Lin, D.H., Ji, J., Long, Z.F., Yang, K., Wu, F.C., 2012b. The influence of dissolved and surface-bound humic acid on the toxicity of $\mathrm{TiO}_{2}$ nanoparticles to Chlorella sp.
Water Res. 46, 4477-4487.

Lin, D.H., Li, T.T., Yang, K., Wu, F.C., 2012a. The relationship between humic acid (HA) adsorption on and stabilizing multiwalled carbon nanotubes (MWNTs) in water: effects of HA, MWNT and solution properties. J. Hazard. Mater. 241 404-410.

Lin, D.H., Liu, N., Yang, K., Xing, B.S., Wu, F.C., 2010a. Different stabilities of multiwalled carbon nanotubes in fresh surface water samples. Environ. Pollut. 158, 1270-1274.

Lin, D.H., Liu, N., Yang, K., Zhu, L.Z., Xu, Y., Xing, B.S., 2009. The effect of ionic strength and $\mathrm{pH}$ on the stability of tannic acid-facilitated carbon nanotube suspensions. Carbon 47, 2875-2882.

Lin, D.H., Ma, S., Zhou, K.J., Wu, F.C., Yang, K., 2015. The effect of water chemistry on homoaggregations of various nanoparticles: specific role of $\mathrm{Cl}^{-}$ions. J. Colloid Interface Sci. 450, 272-278.

Lin, D.H., Tian, X.L., Wu, F.C., Xing, B.S., 2010b. Fate and transport of engineered nanomaterials in the environment. J. Environ. Qual. 39, 1896-1908.

Lin, D.H., Xing, B.S., 2008. Tannic acid adsorption and its role for stabilizing carbon nanotube suspensions. Environ. Sci. Technol. 42, 5917-5923.

Lin, X.C., Li, J.Y., Ma, S., Liu, G.S., Yang, K., Tong, M.P., Lin, D.H., 2014. Toxicity of $\mathrm{TiO}_{2}$ nanoparticles to Escherichia coli: effects of particle size, crystal phase and water chemistry. Plos One 9, 1-8.

Liu, J., Hurt, R.H., 2010. Ion release kinetics and particle persistence in aqueous nano-silver colloids. Environ. Sci. Technol. 44, 2169-2175.

Long, Z.F., Ji, J., Yang, K., Lin, D.H., Wu, F.C., 2012. Systematic and quantitative investigation of the mechanism of carbon nanotubes' toxicity toward algae. Environ. Sci. Technol. 46, 8458-8466.

Lowry, G.V., Gregory, K.B., Apte, S.C., Lead, J.R., 2012. Transformations of nanomaterials in the environment. Environ. Sci. Technol. 46 (13), 6893-6899.

Ma, S., Lin, D.H., 2013. The biophysicochemical interactions on the interfaces between nanoparticles and aquatic organisms: adsorption and internalization. Environ. Sci. Process. Impacts 15, 145-160.

Ma, S., Zhou, K.J., Yang, K., Lin, D.H., 2015. Heteroagglomeration of oxide nanoparticles with algal cells: effects of particle type, ionic strength and pH. Environ. Sci. Technol. 49, 932-939.

Miao, A., Schwehr, K.A., Xu, C., Zhang, S., Luo, Z., Quigg, A., Santschi, P.H., 2009. The algal toxicity of silver engineered nanoparticles and detoxification by exopolymeric substances. Environ. Pollut. 157, 3034-3041.

Miao, A., Zhang, X., Luo, Z., Chen, C., Chin, W., Santschi, P.H., Quigg, A., 2010. Zinc oxide-engineered nanoparticles: dissolution and toxicity to marine phytoplankton. Environ. Toxicol. Chem. 29, 2814-2822.

Oukarroum, A., Samadani, M., Dewez, D., 2014. Influence of pH on the toxicity of silver nanoparticles in the green alga Chlamydomonas acidophila. Water, Air, Soil Pollut. 225, 2038.

Schultz, A.G., Boyle, D., Chamot, D., Ong, K.J., Wilkinson, K.J., McGeer, J.C., Sunahara, G., Goss, G.G., 2014. Aquatic toxicity of manufactured nanomaterials: challenges and recommendations for future toxicity testing. Environ. Chem. 11, 207.

Thio, B.J.R., Zhou, D., Keller, A.A., 2011. Influence of natural organic matter on the aggregation and deposition of titanium dioxide nanoparticles. J. Hazard. Mater. 189, 556-563.

Wang, Z.Y., Li, J., Zhao, J., Xing, B.S., 2011. Toxicity and internalization of CuO nanoparticles to prokaryotic alga Microcystis aeruginosa as affected by dissolved organic matter. Environ. Sci. Technol. 45, 6032-6040.

Zhang, L.Q., Lei, C., Chen, J.J., Yang, K., Zhu, L.Z., Lin, D.H., 2015. Effect of natural and synthetic surface coatings on the toxicity of multiwalled carbon nanotubes toward green algae. Carbon 83, 198-207.

Zhao, J., Wang, Z., Dai, Y., Xing, B., 2013. Mitigation of CuO nanoparticle-induced bacterial membrane damage by dissolved organic matter. Water Res. 47, 4169-4178. 